\title{
Sensoriality and pupil immersive meaning making in a virtual secondary school: A pedagogical avatarial interaction
}

\section{Sensorialité et création de sens par l'immersion des élèves dans un collège virtuel : une interaction pédagogique avatariale}

Caroline Corvasce ${ }^{1}$, Martine Gadille ${ }^{1}$ and Joséphine Rémon ${ }^{2}$

${ }^{1}$ Aix-Marseille Univ, CNRS, LEST, France

${ }^{2}$ ICAR, Université Lyon2, France

\begin{abstract}
We present a study of avatarial interactions in a pedagogical virtual 3D world. We find that there are variations as regards the three dimensions of immersion, symbolic, bodily and social, according to the academic profile of the pupils. The class with a lower mastery of academic skills in maths, French, English and a second language, was found to be more involved with the symbolic immersion aspects, and less with aspects of bodily and social immersion, whereas the class group with a higher mastery of academic skills presented the opposite features. When merging the two class groups, it was the medium high score group that was found to present salient features, namely high indicators as far as the three forms of immersion were concerned.
\end{abstract}

Résumé. Nous présentons une étude d'interactions avatariales dans un monde virtuel 3D pédagogique. Nous mettons en évidence des variations quant aux trois dimensions de l'immersion, symbolique, corporelle et sociale, en fonction du profil académique des élèves. La classe avec un degré moindre de maîtrise académique des compétences en mathématiques, français, anglais et une seconde langue, est identifiée comme plus en prise avec les aspects d'immersion symbolique, et moins avec les aspects d'immersion corporelle ou sociale, tandis que le groupe classe avec un niveau de maitrise supérieur des compétences présente les caractéristiques inverses. Lors de la fusion des deux groupes, c'est le groupe au score moyenélevé qui présente des caractéristiques saillantes, plus précisément des indicateurs élevés en ce qui concerne les trois dimensions de l'immersion. 


\section{Introduction}

In this paper we explore sensoriality and pupil engagement in a virtual Secondary School, around pedagogical avatarial interactions. Haza (2020:11), in her study of video games in psychotherapy, reckons that the specific element that promotes play and the impression of illimited creativity, resides in the sensoriality that comes with a video game (musique, sounds, light, luminosity, colours), and is able to capture the player's senses. For this author, the sensorial stimulation, perhaps even before the projection of the player's body in the avatar, and the symbolism of the avatars' actions, engages the players' sensoriality. It is this sensoriality that we wish to explore, not in the context of a video game but in the context of a pedagogical 3D world, in relation with the dimensions of pedagogical immersion in this world and its wider context of use, a French pilot secondary school.

\section{Context of the study and theoretical background}

The data we analyze comes from the interactions taking place within a pedagogical virtual world based on Open Simulator (figure 1), the type of platform used for online collaborative gaming. The platform is not gamified as such: it is up to the teachers to create scenarios.

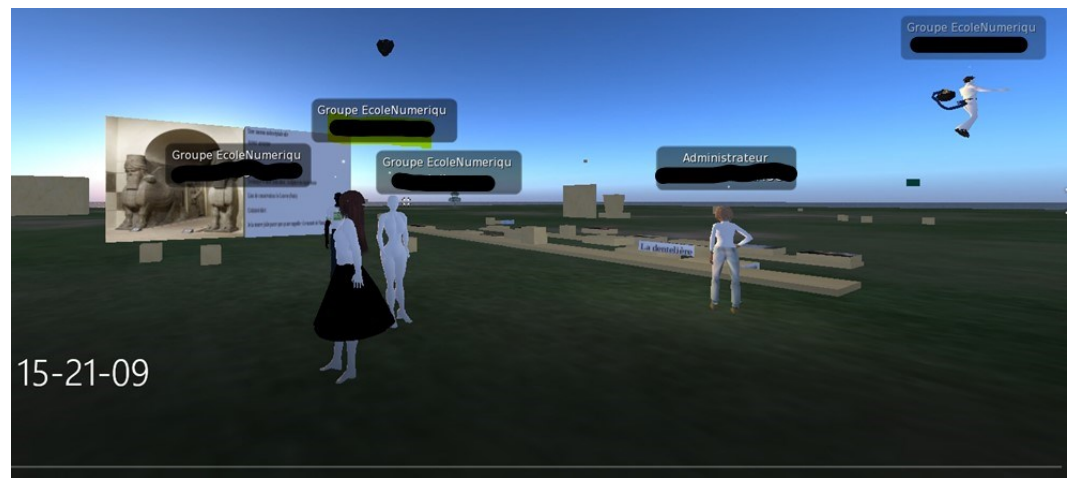

Figure 1. A scene from the virtual pedagogical world based on Open Simulator.

Why use a $3 D$ world at school?

The general context of the study is a pilot French secondary school, where the teachers have been using the $3 \mathrm{~d}$ world since 2016, as part of the "e-PiM" project (Incubator of Immersive Pedagogy for Virtual Reality), involving pupils from 11 to 15 years old. The project is part of the "Digital Plan for Education" launched by the French government in May 2015, involving the distribution of tablets in the school district as part of the "Connected Secondary schools" scheme. The school started the digital experimentation in 2016, after obtaining financial support through this national funding plan. One teacher in particular played a key role in making the use of the 3D world more widespread within the school, ending up recently creating his own company. This maths teacher not only uses the virtual world but was indeed also the instigator for the whole project, and trains the pupils and colleagues in their first contact with the platform, playing an important role in the individual and collective appropriation of the tool. The $3 \mathrm{D}$ world is used regularly during class in the computer room, and by the pupils at home for tutored homework sessions.

The study of sensoriality

The study of sensoriality is the study of the condition of being sensorial or being a sensations/senses prone individual. The theoretical context of our study draws on a multidisciplinary approach to better apprehend sensoriality, bodily immersion, and the different uses of virtual worlds in the classroom as coined in the literature. Indeed, as Pink puts it (2010: 332): "Contemporary anthropological work around the senses is emerging in parallel and sometimes in relation to similar developments in sensory geography, sociology, psychology and the 'interdisciplines' of health studies, sports studies, learning studies and more". In the particular case of our study, we combine learning studies with psychology, workplace sociology, and management sciences.

Sensoriality and screens

The link between sensoriality and screens is identified for instance by Poissant (2003: 3), who explains that interacting with screens allows us to discover new forms of sensoriality : « By touching the screen, we can make images appear, a breath activates a device, a movement generates music. Interfaces surreptitiously introduce other ways of relating to others and to the world and, by way of sequence, other ways of feeling and perceiving oneself. Unexpected nerve endings are discovered, areas of sensitivity that are still untested » (our translation). So indeed studying the interactions in an educational virtual world from the point of view of sensorialities makes sense, since the screen mediates the learning. 


\section{Sensoriality and virtual reality}

Moreover, beyond the use of the screen, from the point of view of Virtual Reality itself, Chatelet and Di Costa (2018: 270) link sensoriality and the capacity of virtual reality to trick our perceptive modes by questioning our corporeity and sensoriality in a multiodal interactive immersion, that is sensori-motor, cognitive, physiological and emotional. So again, our studying the use of an educational virtual world from the point of view of sensoriality contributes to shedding light on this tackling of our perceptive modes, in our case specifically in the light of meaning making and learning.

\section{Sensoriality and language}

The link between sensoriality and language is present in the enaction theory, and eplxained in the works of authors such as Eschenauer $(2020: 8)$ in these words: "In the theoretical framework of enaction, sensoriality, emotions and empathy constitute means of the relationship, thus modalities of language"; "among the physiological factors mediating the signifying/signified meaning of the situation experienced, sensoriality holds a central place" (ibid.: 14). This link is relevant for our study since meaning making in an educational setting uses language, and the use of a 3D World reshapes sensoriality, which is closely intertwined with language.

\section{Sensoriality, embodied cognition and learning}

More generaly, we indeed consider sensoriality from the point of view of embodied cognition. Cognition is a biological phenomenon implying the whole body (Malouin 2019; Levent et Pascual-Leone, 2014) which brings Bottineau (2011) to speak about the corporeity of meaning-making. Indeed, embodied cognition revisits the role of the body and the senses in cognition, which makes the study of sensoriality relevant for the understand of cognition, learning and meaning-making. In this approach, language interactions in learning are seen as not just a representational construct, but as enaction (Varela et al., 1993). We explore the modalities of this enaction, in order to understand the link between sensoriality and embodied cognition within the mediation of the virtual world.

Other authors have studied Virtual Reality and learning such as Henderson et al. (2018), from the point of view of the relationship between learner cognition and instructional design, or Lan and al. (2015) from the point of view of language learning, or else Gillen et al (2012) from a problem-solving perspective.

As far as learning and embodied cognition are concerned, in the context of a virtual world, Privas-Bréauté (2017: 29) speaks about a new "pedagogical corporeity". And in the case of language learning, for example, she formulates that the body and our emotions are part of the language learning process, including when it is the avatars body that's involved.

\section{Immersion and learning}

As for the link between immersion and learning, Dawley and Dede phrase it in these words (2014: 3): "Immersive technologies provide alternative environments for situated learning, because an almost endless variety of virtual contexts are available, or can be created, that give users a sense of "being there," [...] and thus, the ability to apply learning in a plausible, unique context".

Following these authors, in this paper we study sensoriality in the use of a 3D virtual world according to the 3 dimensions of immersion that they have identified: 1) the symbolic dimension in relation to the narrative aspects and the pedagogical scenarios, 2) the physical dimension in relation to the body of the player and 3) the social dimension in relation to interactions with the peers and teachers in the virtual world. We use these dimensions of immersion from the point of view of sensoriality to shed light on meaning-making and embodied cognition in the pedagogical virtual world.

The question we are asking is: how does sensoriality act as a vector for immersive meaning-making and learning in the virtual secondary school?

\section{Corpus and methodology}

The corpus treated in the present paper, is composed of a survey submitted to 2 class groups of 13 year old pupils (22 and 14 pupils in june 2019). Since there were only 36 pupils in this study, we consider this an exploratory research for hypotheses building. This survey is part of a wider corpus which is managed on the HUMANUM platform. Other data collected consist of skills assessments, data about class atmosphere as conveyed by school reports, teacher preparation sheets for the different scenarios (2018-2019), recorded interviews with the teachers and the pupils, and in-world and classroom scenario ethnographic observations.

Several scenarios were implemented for the two classes observed. Some of them lasted one hour and were repeated several times (mathematics) and three scenarios lasted several months during the school year. Of these three scenarios, the first was interdisciplinary and involved the French teacher, the English teacher, the Spanish teacher and the mathematics teacher around a pedagogical project entitled "seven wonders of the ancient world". The French teacher used this theme to work on the fundamental knowledge of the year 8 in French secondary school: consolidation of grammar, conjugation and familiarisation with literature. A second scenario in Italian language was based on a weekly language exchange with a class in Italy using the same virtual platform where the pupils displayed photos and texts (in the foreign language) about the culinary and cultural specialities of their region or town on 3D panels. A third scenario in English language was based on the training for a national competition (Big challenge) based on quiz. 
Given that this experiment involved two classes only, and different subjects, we did not primarily seek to analyse acquisition in relation with tasks using the virtual world. We focused rather on the transformation of learning conditions in general in the two classes studied, based on the transformation of sensoriality and the creation of meaning in the virtual world, compared to learning in the classroom, where children sit and mobilise the notebook or sheets of paper and a pencil case to carry out exercises.

More precisely, the tools used for data collecting on the use of the virtual world are videos shot in the classroom while the pupils use the virtual world, and simultaneous screen recordings by a researcher present in the virtual world through an avatar.

This data was collected by an interdiscipinary team (psychology, sociology, learning sciences, management science) with in view an interdisciplinary treatment of the data in order to better apprehend the interdependent nature of the interactions at stake (Gadille et al., 2021). The analyses we present here use more precisely the survey and the skills assessment sheets.

Skills assessments were undertaken in order to calculate an average competence for each pupil, with regards to French, Maths, English, and a second language. This assessment allowed to distinguish 3 groups around scores from 1 (low mastery of the given skills) to 4 (good mastery of the given skills), and then an average of the scores for the 4 subjects: the group with lower scores $(1<2,5)$ with a mastery of the skills under average, the group with medium scores $(2,5<3,5)$ with an intermediate mastery of the skills, and the group with high scores $(3,5<4)$ with an advanced mastery of the given skills.

We will present first a global comparison between the two classes involved, around the 3 immersion dimensions: physical, social and symbolic. Then we will focus on the medium score group, which appears to have some specific indicators.

The questions asked as paramaters for each type of immersion were:

1. for the symbolic dimension in relation to the narrative aspects and the pedagogical scenarios:

- I like working in the virtual world for French

- I like working in the virtual world for Maths

- I like working in the virtual world English

- I like learning, reviewing things related to the course

2. for the physical dimension in relation to the body of the player

- I like flying

- I like walking

- I like falling from the sky

- $\quad$ Ilike to dress my avatar

- I like building or creating things

- I like exploring

3. the social dimension in relation to interactions with the peers and teachers in the virtual world

- I like interacting with my peers

- I like interacting with the teachers

An open question was added at the end of the questionnaire: "I like working in the CV because".

\section{Global comparison between the two classes}

The two classes, overall, do not present the same score averages. We look at the three types of immersion for each class.

\subsection{Symbolic immersion in relation with academic skills}

Indeed, from the point of view of the different types of immersion, in the class where the pupils have generally more academic difficulties (in blue on the chart, class 5D in figure 2), the pupils seem to be more into symbolic immersion, that is to say, they declare being more influenced by the pedagogical scenario, than the pupils in the class with generally fewer academic difficulties. 


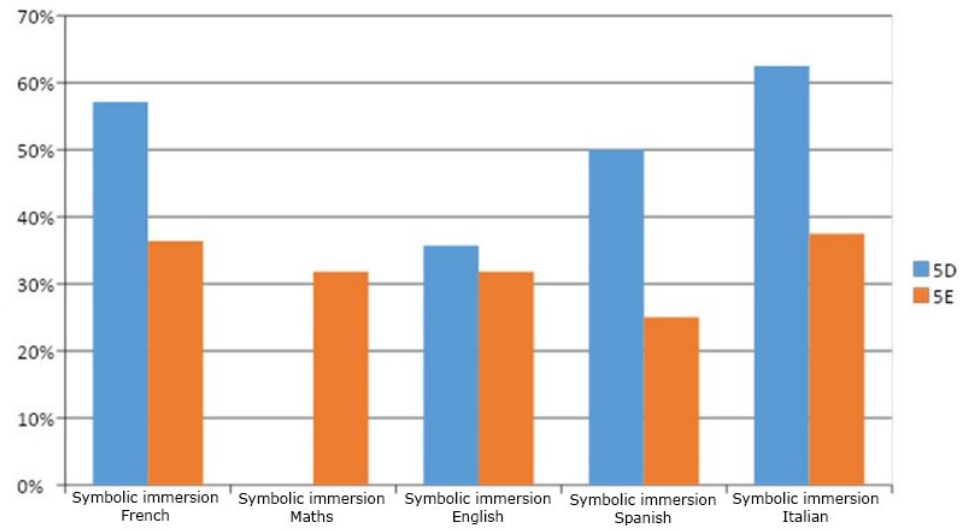

Figure 2. Comparison between the two classes from the point of view of symbolic immersion.

There is no indicator in maths for class 5E because their maths teacher doesn't use the virtual world.

\subsection{Bodily immersion in relation with academic skills}

We have coined bodily immersion in relation to the answers given by the pupils to questions about liking to fly, walk, fall from the sky, dressing the avatar (figure 3), building, exploring.

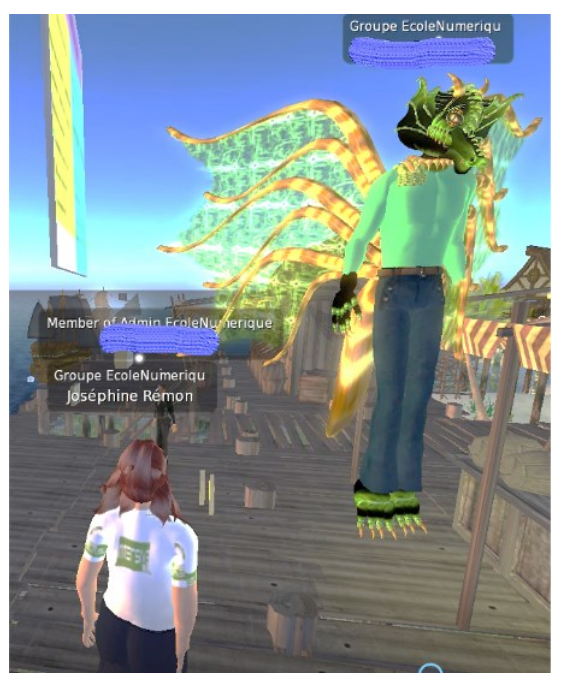

Figure 3. Making the avatar fly, and dressing the avatar.

In the class with more difficulties (blue on the chart, figure 4), the pupils appear to be less motivated by bodily immersion. 


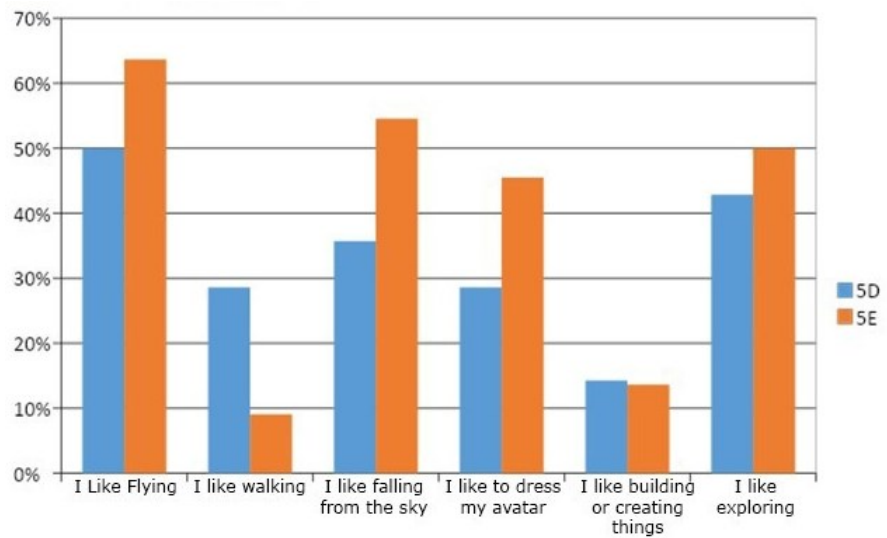

Figure 4. Comparison between the two classes from the point of view of bodily immersion.

In the class with fewer difficulties (in orange on the chart, figure 4), half or more of the pupils declare liking to fly, dress the avatar and explore. During the interviews, the pupils insist on the fun aspects of the Virtual School. For example, Lina says " it's more fun than a normal class », Florian says «I can create, explore and have fun », or Mathélian says "we can build and fly".

\subsection{Social immersion}

On the other hand, still in the class with fewer difficulties, the pupils seem to be less involved with social immersion (figure 5). We have coined the dimension of social immersion in relation with questions about relations with the peer and teachers ("I like to interact with my peers", "I like to interact with the teachers").

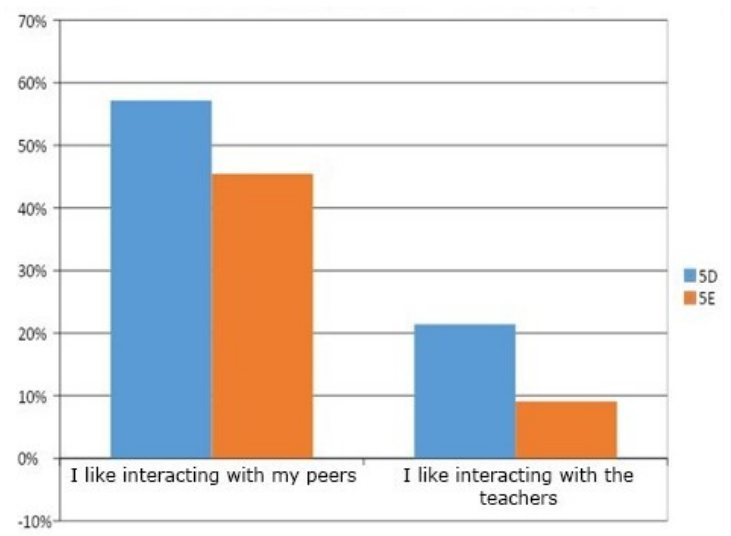

Figure 5. Comparison between the two classes from the point of view of social immersion.

For these pupils with fewer academic difficulties the interactions with other peoples or with the teachers are perhaps less important than for pupils who have more difficulties.

\subsection{Summary: the 3 types of immersion when comparing the two classes}

If we come back to our question about sensoriality and immersion dimensions, and sum up the saliencies we have identified so far, we see that in the class with more difficulties (blue on the chart), the pupils seem to be more involved into symbolic immersion and social immersion, and less into bodily immersion. In the class with fewer difficulties (orange on the chart), the pupils seem to be less involved into social immersion and symbolic immersion, and more into bodily immersion. We will discuss these findings in the "discussion" section below. 


\section{The average skills group}

Our second part focuses on what we called the average skills group, this time, not in a particular class group, but merging the two classes, always around the questions of the three dimensions of immersion as regards sensoriality and academic profiles.

\subsection{Symbolic immersion}

When merging the two classes, the average-high group presents specific indicators for symbolic immersion (figure 6), thus pointing at the fact that the pupils that have an above average mastery of academic skills, within the average skills group, are those who potentialize the affordances offered to them.

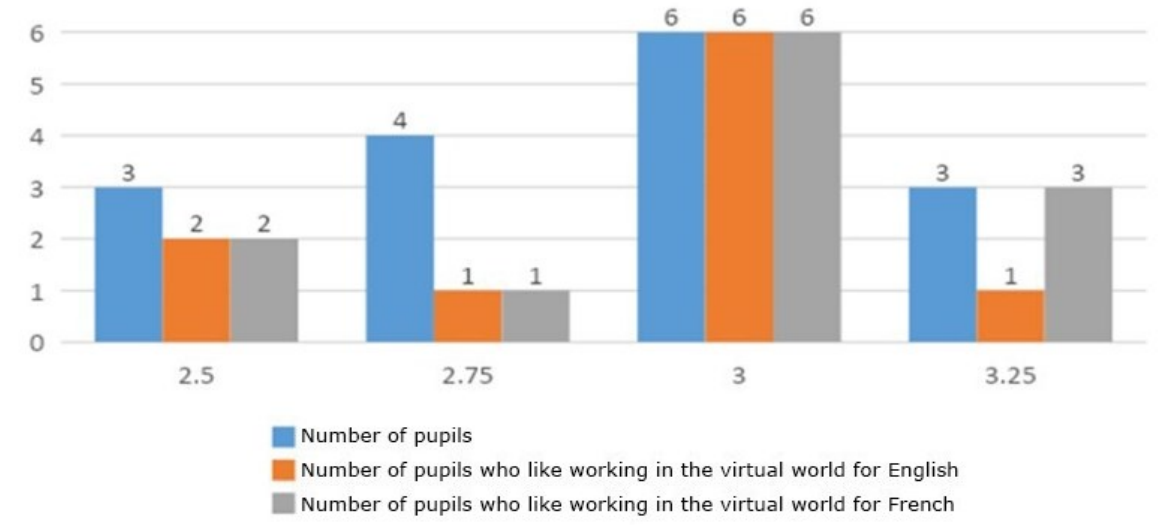

Figure 6. Symbolic immersion for the average score group.

\subsection{Bodily immersion}

Indeed, when merging the two classes and looking at the results in this way, the group with average results seems indeed to present specific values for the indicators around a bodily immersion. And if we look inside this average group, the pupils with an average high score also seem to present specific values for the indicators around bodily immersion, such as liking to letting themselves fall onto the ground or liking flying.

When merging the two classes, the average group presents high scores for bodily immersion (figure 7).

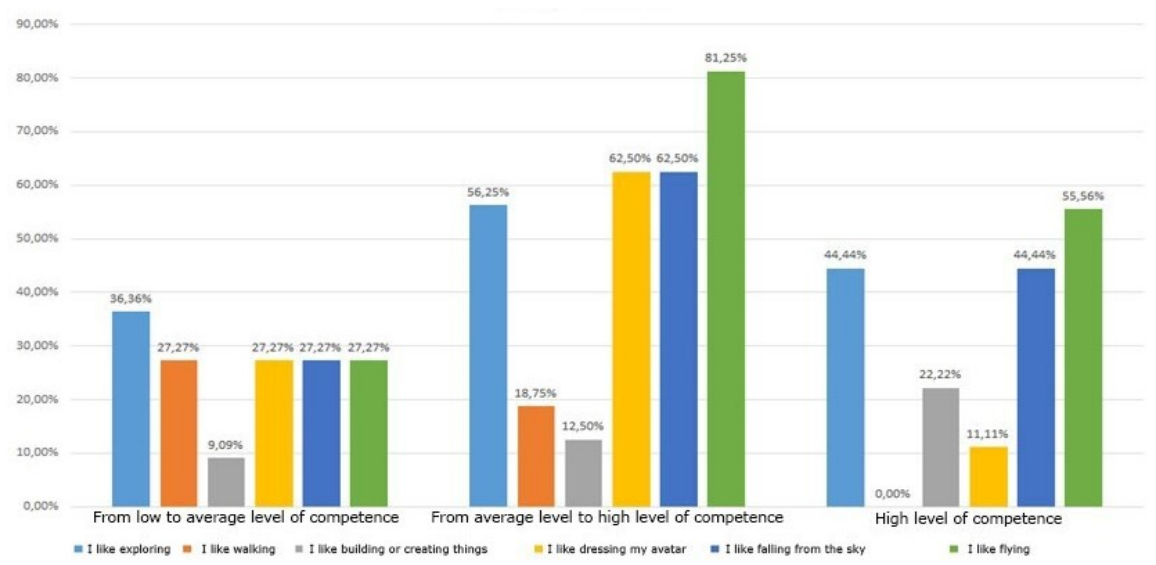

Figure 7. Physical immersion according to the skills assessment results.

Within the average group, the pupils with an average-high score also present specific indicators for bodily immersion (figure 8). 


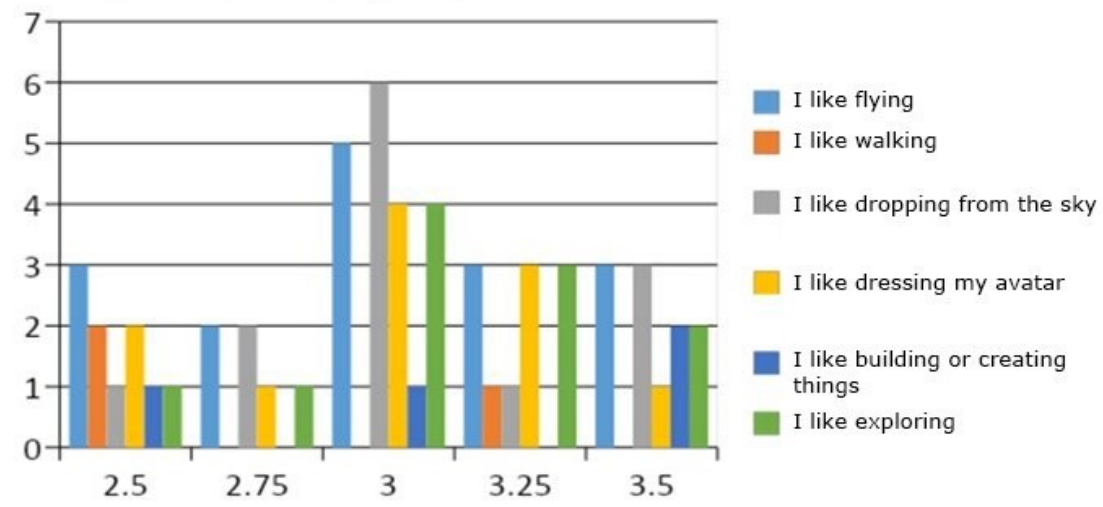

Figure 8. Indicators for bodily immersion within the average score group.

\subsection{Social immersion}

When merging the two classes, the average-high group presents specific indicators for social immersion (figure 9).

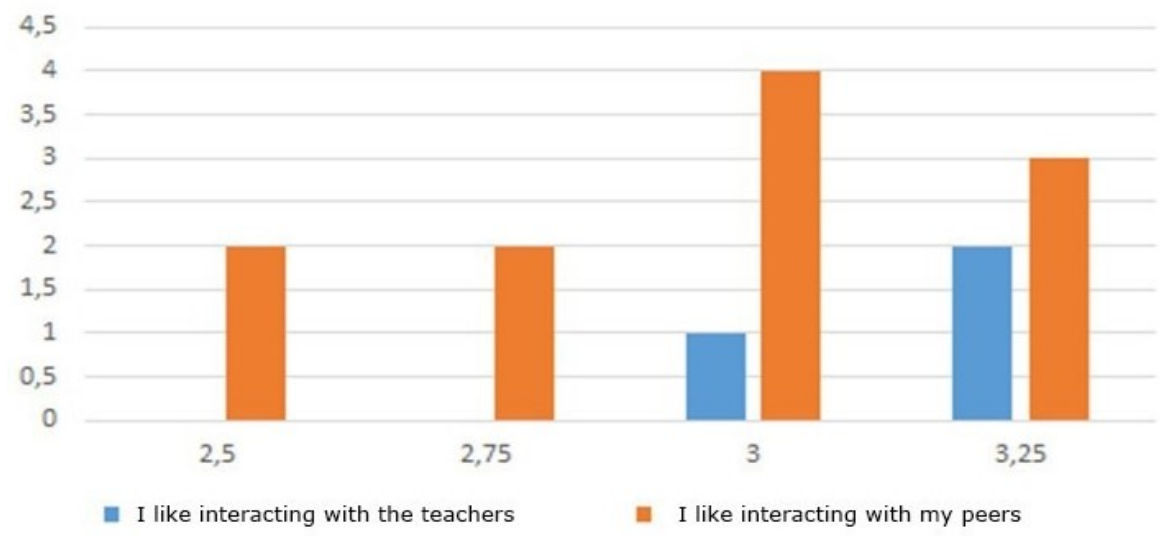

Figure 9. Social immersion for the average score group.

The most competent pupils within this group with an average mastery of academic skills, are also those who seize the opportunity of interacting with the teachers.

\subsection{Summary: Immersion and sensoriality for the average group}

When merging the two classes, the group with average scores for academic skills presents high scores for bodily immersion. Within this average group, the average-high score sub-group also presents specific indicators for bodily immersion: falling, flying, exploring, dressing the avatar. Furthermore, the average-high score group presents specific indicators for social immersion: interacting with the teachers but more so with other pupils. And finaly, this same average-high score group presents specific indicators for symbolic immersion: the pupils in this group seem more into pedagogical aspects than the top group.

\section{Discussion}

We have shed light on some salient elements, around the question of sensoriality and immersive meaning-making in a pedagogical virtual world. The average group, that was identified according to academic results, seems to be reacting in a specific way. Indeed what we saw was that when merging two classes object of the study, the group with average scores for academic mastery, presents high scores from the point of view of bodily immersion. Within this average group, it is the average-high score group that seems to present specific indicators, again, for bodily immersion (falling, flying, exploring, dressing the avatar), social immersion (i.e. interacting with the teachers, but even more so with other 
pupils), and symbolic immersion (which means they seem more into pedagogical aspects than the very top group). In other words, pupils with average results seem more responsive to the 3 dimensions of immersion (social, bodily, symbolic).

Our analysis tends to suggest that pupils with more difficulties focus on pedagogical aspects and less on exploring the virtual world. For these pupils, one could suppose that socializing and being offered pedagogical innovations in the virtual world would be an opportunity, but are they really able to seize pedagogical opportunities when they are presented through a different medium? They do seem to have an interest in the pedagogical scenario and in exchanging with their peers and with the teachers.

This questions more generally the prerequisites that allow some pupils to seize opportunities in the 3D World. Which pupils have enough mastery of academic skills to be able to pay attention to bodily aspects? How does academic " format » conflict with sensoriality? Indeed there may be a conflict between what the pupils think is authorised or expected in the virtual world, and which opportunities they would actually seize outside these conflicts? Do they feel entitled to seize the fun aspects of the 3D platform?

Further studies need to be undertaken to shed light on what appears to be a lack of bodily immersion for certain pupils and what it means for the teacher or the use of "virtual worlds » in general in the classroom. We might ask in which way this is related to specific configurations or whether it is a general tendency, and if so, why. This is the reason for the choice we have made for the 20-21 data collection, focusing on pupils with academic difficulties, in order to document these tendencies further.

We wish to further investigate the link between bodily aspects in the virtual world and the place of the body for pupils who are struggling from an academic point of view, under the double domination of French school elitism and social structures that endow children, in a very uneven way, with the predisposition for learning at school thanks to the family's invisible pedagogy (Bernstein, 1975; Beaudelot and Establet, 2009), We are currently questioning to what extent school form can be deconstructed in the virtual world in order to open up opportunities for pupils who experience difficulties under academic norms and power struggles.

\section{Conclusion}

Our findings would point to a relation to sensoriality that would depend on the pedagogical scenario and the affordances developed around the 3D platform, but also on personal habilities and beliefs. Still to be explored would then be the set of parameters that would help define sensorial regimes for embodied learning in a virtual world, combining an intertwined individual and social apprehension of affordances, each influencing the other.

Following the steps of Privas-Bréauté (2017) in her defining of a "pedagogical corporeity", we will continue investigating an avatarial pedagogical sensoriality, with at heart the imperative that no pupil should be left behind, however seductive the technical innovation might be.

\section{References}

Bernstein Basil. (1975). Langage et Classe sociales, Paris Editions de Minuit, Le sens commun.

Bottineau Didier. (2011). Parole, corporéité, individu et société: l'embodiment entre le représentationnalisme et la cognition incarnée, distribuée, biosémiotique et enactive dans les linguistiques cognitives. Intellectica - La revue de l'Association pour la Recherche sur les sciences de la Cognition (ARCo), Association pour la Recherche sur la Cognition, p.187-220. halshs-00656024

Chatelet Claire, Di Crosta Marida. (2018). Écran incorporé, corps casqué. Interfaces numériques, vol. $7, \mathrm{n}^{\circ} 2$. http://dx.doi.org/10.25965/interfaces-numeriques.3375

Eschenauer Sandrine. (2020). « Le corps translangageant médiateur de sens », TIPA. Travaux interdisciplinaires sur la parole et le langage [En ligne], $\mathrm{n}^{\circ} 36$, mis en ligne le 01 juin 2020, consulté le 15 avril 2021. URL: http://journals.openedition.org/tipa/3672; DOI : https://doi.org/10.4000/tipa.3672

Dawley Lisa, Dede Chris. (2014). "Situated learning in virtual worlds and immersive simulations", in J. M. Spector, in M.D. Merrill, J. Elen, \& M. D. Bishop (eds), Handbook of research on educational communications and technology, 4th ed., , NY: Springer, New York, p. 723-734.

Gadille Martine, Impedovo Maria, Corvasce Caroline, Rémon Joséphine (in press, 2021). Interdependent creativity for Learning in a Virtual World, Journal of Information and Learning Sciences, Emerald ed., in press, 2021

Gillen Julia, Ferguson Rebecca, Peachey Anna, Twining Peter. (2012). Distributed cognition in a virtual world, Language and Education, vol. 26, $\mathrm{n}^{\circ}$ 2, p. 151-167, doi : 10.1080/09500782.2011.642881

Haza Marion. (2020). Du jeu vidéo en psychothérapie : un habile mélange de récits et de sensorialités. Enfances \& Psy, vol. $85, \mathrm{n}^{\circ} 1$, p. 119-129. https://doi-org.bibelec.univ-lyon2.fr/10.3917/ep.085.0119

Henderson Michael, Henderson Lyn, Grant Scott, Huan Hui. (2018). Cognitive engagement in virtual worlds language learning. In Sue Gregory \& Denise Wood (Eds.), Authentic Virtual World Education: Facilitating Cultural Engagement and Creativity (1st ed., p. 117-134). Springer. https://doi.org/10.1007/978-981-10-6382-4_8 
Lan Yu Ju, Chen, Nian Shing, Li Ping, Grant Scott. (2015). Embodied cognition and language learning in virtual environments. Education Tech Research Dev, n 63, p. 639-644. https://doi.org/10.1007/s11423-015-9401-x

Levent Nina, Pascual-Leone Alvaro. (Eds.). (2014). The Multisensory Museum: Cross-Disciplinary Perspectives on Touch, Sound, Smell, Memory, and Space. Lanham, MD: Rowman \& Littlefield.

Malouin Sophie. (2019). "La sensorialité cognitive de l'expérience muséale”. Animation, territoires et pratiques socioculturelles (Revue ATPS), vol. 15, p. 19-30.

Pink Sarah. (2010). with response by David Howes. The future of sensory anthropology/the anthropology of the senses. Social Anthropology/Anthropologie Sociale, vol. 18, n³, p. 331-340. doi:10.1111/j.1469-8676.2010.00119.x

Poissant Louise. (2003). Interfaces et sensorialité. Presses de l'Université du Québec.

Privas-Bréauté Virginie. (2017). Développement cognitif et apprentissage de l'anglais langue des affaires en IUT à travers le jeu : utilisation des mondes virtuels. Recherche et pratiques pédagogiques en langues de spécialité [En ligne], Vol.36 $\mathrm{N}^{\circ} 2$, mis en ligne le 29 juin 2017, consulté le 18 juin 2019. URL : http://journals.openedition.org/apliut/5740 ; DOI : 10.4000/apliut.5740

Varela Francisco, Thompson Evan, Rosch Eleanor. (1993). L'inscription corporelle de l'esprit. Sciences cognitives et expérience humaine. Paris : Seuil. 